\title{
The relationship of dementia prevalence in older adults with intellectual disability (ID) to age and severity of ID
}

\author{
A. Strydom ${ }^{1 *}$, A. Hassiotis ${ }^{1,2}$, M. King ${ }^{1,2}$ and G. Livingston ${ }^{1,2}$ \\ ${ }^{1}$ Department of Mental Health Sciences, Royal Free and University College Medical School, UCL, London, UK \\ ${ }^{2}$ Camden and Islington NHS Foundation Trust, London, UK
}

Background. Previous research has shown that adults with intellectual disability (ID) may be more at risk of developing dementia in old age than expected. However, the effect of age and ID severity on dementia prevalence rates has never been reported. We investigated the predictions that older adults with ID should have high prevalence rates of dementia that differ between ID severity groups and that the age-associated risk should be shifted to a younger age relative to the general population.

Method. A two-staged epidemiological survey of 281 adults with ID without Down syndrome (DS) aged $\geqslant 60$ years; participants who screened positive with a memory task, informant-reported change in function or with the Dementia Questionnaire for Persons with Mental Retardation (DMR) underwent a detailed assessment. Diagnoses were made by psychiatrists according to international criteria. Prevalence rates were compared with UK prevalence and European consensus rates using standardized morbidity ratios (SMRs).

Results. Dementia was more common in this population (prevalence of $18.3 \%$, SMR 2.77 in those aged $\geqslant 65$ years). Prevalence rates did not differ between mild, moderate and severe ID groups. Age was a strong risk factor and was not influenced by sex or ID severity. As predicted, SMRs were higher for younger age groups compared to older age groups, indicating a relative shift in age-associated risk.

Conclusions. Criteria-defined dementia is 2-3 times more common in the ID population, with a shift in risk to younger age groups compared to the general population.

Received 26 October 2006; Revised 28 February 2008; Accepted 6 March 2008; First published online 15 April 2008

Key words: Alzheimer's disease, brain reserve, dementia, intellectual disability, mental retardation.

\section{Introduction}

It has often been assumed that dementia occurs more commonly in the intellectual disability (ID) population than in the general population (Torr, 2005). Although it is now accepted that those with Down syndrome (DS) have a genetic predisposition for dementia related to the APP gene on chromosome 21, dementia may also be more common in the ID population who do not have DS (Cooper, 1997). Furthermore, it has been proposed that dementia in the ID population should occur at a younger age than is usual. Tredgold, a London physician during the first half of the previous century, asserted that 'as would be expected, in most cases of primary amentia, [the] senile form of

* Address for correspondence: Dr A. Strydom, Department of Mental Health Sciences, Royal Free and University College Medical School, UCL Hampstead Campus, Rowland Hill Street, London NW3 2PF, UK.

(Email: a.strydom@medsch.ucl.ac.uk) dementia sets in at an earlier age than the normal. It often begins to show itself in the fourth decade [...], and the majority of aments who live much after this usually show definite and progressive mental deterioration' (Tredgold, 1952). Thompson (1951) believed the earlier age of decline to be related to arrested brain development.

More recently, the cognitive reserve hypothesis has been proposed to explain how adults with similar brain insults may present with differing clinical pictures. It proposes that intelligence, education and occupational level can influence the occurrence and course of many central nervous system disorders (Whalley et al. 2004). Stern (2002) proposed two components to cognitive reserve. The first comprises passive components such as brain size and synapse count or 'hardware' of the brain, which differs between individuals. Proxies for it include measurements such as brain volume and pre-morbid intelligence (Staff et al. 2004). Active components or 
'software' of the brain are developed through educational, leisure and occupational activities that develop the use of different neuronal pathways (Stern, 2003). The hypothesis assumes that there is a critical threshold of reserve capacity that needs to be breached by pathological processes before clinical or functional symptoms will develop. Those with more reserve have been found to be less likely to develop dementia or cognitive decline (Whalley et al. 2000; Verghese et al. 2003; Valenzuela \& Sachdev, 2006). Although these studies are consistent with the theory of cognitive reserve, none specifically studied participants in the ID (mental retardation) range of ability.

Adults with ID have, by definition, brain reserve limitations. In addition, many older adults with ID in developed countries have been excluded from education (Randall Smith, 2005) and have for long periods resided in large, environmentally impoverished institutions. The cognitive reserve hypothesis predicts that older adults with ID should be particularly at risk for dementia and that the age-associated risk should be shifted to a younger group because, theoretically, those with dementia pathology will quickly reach a functional cut-off with early emergence of symptoms; it also indicates that dementia risk should differ according to the severity of disability.

Despite the long-held assumption that dementia is more common in older adults with ID without DS, there have been only a few small community surveys of dementia prevalence in this group of adults and we have not been able to find any studies that have investigated their age-associated risk or the potential effect of ID severity on dementia rates.

We aimed to examine the following:

(1) Prevalence of dementia in older adults with ID compared to general population prevalence.

(2) The differences, if any, of dementia prevalence rates between ID severity groups.

(3) We also hypothesized that the excess risk for dementia [standardized morbidity ratios (SMRs) based on prevalence rates] would be greatest in 'younger' older adults with ID.

\section{Method}

We undertook a two-stage epidemiological survey of dementia in adults with ID without DS aged $\geqslant 60$ years living in five inner-city and suburban London boroughs: Camden, Islington, Enfield, Harrow and Greenwich. Adults with DS were excluded because of their known genetic risk for Alzheimer's disease. The protocol received approval from the Thames Valley Multi-centre Research Ethics Committee and was agreed with the $R \& D$ offices of all participating National Health Service organizations.

\section{Definition of participants}

ID was defined according to ICD-10 criteria for mental retardation (WHO, 1993) as global developmental delay, IQ $<70$ and impairment of social functioning. Those in whom the ID status was uncertain at screening underwent an assessment and were excluded if they did not meet these ICD-10 criteria. Each participant's severity of ID was rated to be mild, moderate or more severe, according to their early life abilities (including IQ if available) and current skills.

Adults with DS were identified from chromosomal analysis in their records or by their characteristic features, and were excluded from the study.

\section{Identification of participants}

All adults with ID aged $\geqslant 60$ years, who were currently resident in any of the five boroughs, were identified from:

(1) Social services electronic databases (current and past recipients of social care who have been recorded at any time to have ID).

(2) Any past or present users of the local ID healthcare teams.

(3) All local residential and day services providers (voluntary or government sector) for adults with ID.

(4) In two of the boroughs we also made contact with all geriatricians, old age psychiatrists, mental health teams for older people, and all non-ID residential and nursing homes. This extension of the sampling frame did not result in significant numbers of additional participants, and was not used in the other boroughs.

\section{Contact with participants and consent procedures}

An information sheet that used simple words, short sentences, large text and pictures was sent to the potential participants and their carers. Potential participants decided on their own participation if they were able. For those that did not have capacity to consent, we sought agreement from carers and willingness by participants to engage with procedures. We also gained consent from informants for their own participation in the survey. Informants were family members, social workers or care staff who had regular contact with the participants. They must have known the participant for at least 3 months to complete the Dementia Questionnaire for Persons with Mental Retardation (DMR) and at least 2 years to provide information on longitudinal change; if necessary, further informants or historical records were sought. 


\section{Screening stage}

All participants were screened for symptoms of dementia or cognitive decline with:

(1) The DMR (Evenhuis, 1996), a validated informantcompleted screening tool for dementia in this population. The tool has two scales: a cognitive scale, based on short- and long-term memory and orientation; and a social scale, based on functional and behavioural items. Each scale has different threshold scores for different ID severity groups. We used the cognitive scale and its published thresholds for severe, high moderate or mild ID for the three ID severity groups in our study.

(2) Informants also completed a brief activities of daily living schedule (ADLs), based on the Adaptive Behaviour Scale (Nihira et al. 1992) and Activities for Daily Living Schedule (Lawton \& Brody, 1969), and any decline in ADLs over the past 2 years was determined. Information about level of functioning in early life was also collected from informants.

(3) Participants with ID with sufficient communication skills completed a three-item object memory task based on a modified object memory task (Shoe Box Test; Burt \& Aylward, 2000).

Screen-positive criteria were inclusive so that no dementia cases would be missed. Therefore, screen positives were those who scored at or above the cognitive score thresholds on the DMR; or had unexplained decline in ADLs; or had a delayed recall of less than two out of three items in the Shoe Box Test task. Participants who screened negative on these criteria were deemed not to have dementia.

\section{Assessment of screen positives}

Participants who screened positive completed a full assessment to elicit symptoms of dementia and to identify disorders pertinent to a differential diagnosis. The assessment included:

(1) Cognitive functioning and symptoms of dementia:

(a) A neuropsychological assessment, consisting of the Test for Severe Impairment (Albert \& Cohen, 1992), additional memory items from the Severe Impairment Battery (Saxton \& Swihart, 1989), the Tower of London (Shallice, 1982), Supermarket Fluency task (Troyer, 2000), British Picture Vocabulary Scale (Dunn et al. 1997) and Luria three-stage command.

(b) Informants completed an additional questionnaire based on a modification of the CAMDEX informant questionnaire (Ball et al. 2004) to elicit a history of changes in memory, personality, general cognitive function and confusion.
(2) Physical health

(a) A structured physical examination identified neurological signs associated with dementia and also signs of any other relevant physical condition, such as thyroid disorders, neurological conditions and cardiovascular disorders. This was based on the procedures for such assessments used previously (Hassiotis et al. 2003), and a vision and hearing screen.

(b) Informants provided information about current physical health and medications. In addition, we reviewed available medical records to record information on previous health status and recent investigations.

(3) Psychiatric disorders other than dementia were determined by:

(a) A brief mental state examination with the participants.

(b) Informants completed the mini-PASADD (Psychiatric Assessment Schedule for Adults with a Developmental Disability), a specific tool for adults with ID (Moss, 2002).

\section{Diagnosis}

We collated all information in anonymized summaries for independent diagnostic review by two of three psychiatrists (A.H., G.L. or A.S.), two of whom (A.H. and A.S.) are specialists in the psychiatry of ID and the other (G.L.) a specialist in old age psychiatry. An instrument developed to produce a hierarchical differential diagnosis of dementia in this population was used to determine whether the participants met any criteria for dementia [ICD-10 (WHO, 1993) or DSM-IV (APA, 2000), dementia with Lewy bodies (DLB; McKeith et al. 1996) or fronto-temporal dementia (FTD; McKhann et al. 2001)]. This took account of the person's level of ability, the presence of autistic spectrum disorders, physical and mental disorders or sensory deficits as well as changes in the environment. The diagnostic process and how disagreements were resolved are described elsewhere (Strydom et al. 2007). The participants were then divided into three groups: those with criteria-defined dementia (if they met any of the above diagnostic criteria), potential cases (if there was insufficient information to decide either way), or those who definitely did not have dementia (no dementia).

\section{Analysis}

Data was entered into SPSS version 11 (SPSS Inc., Chicago, IL, USA). The $\chi^{2}$ statistic was used to analyse categorical variables (e.g. sex and ID level by participation or not) unless any cell had an expected count of 
$<5$, in which case Fisher's exact test was undertaken. We used $t$ tests to analyse differences in mean age by screen-positive or dementia status. Prevalence rates are presented as percentages. We calculated 95\% symmetrical exact binomial confidence intervals (CIs) with a calculator available at http://statpages.org/ confint.html.

The indirect method was used to make comparisons with general population rates in 5-year bands. The most recent Western European general population consensus prevalence rates (Ferri et al. 2005) were used to calculate expected counts for dementia for this study because it provided the only available estimate of dementia prevalence in adults aged $\geqslant 60$ years. Further comparison was made for adults aged $\geqslant 65$ years using actual prevalence rates obtained from the MRC Alpha study (Saunders et al. 1993). This study is the one of the largest and most recent UK dementia prevalence studies in urban populations for which data are readily available, and forms part of the well-known European studies of dementia prevalence (EURODEM). The observed count divided by the expected count provided SMRs for all these comparisons (Page et al. 1995). CIs for SMRs were calculated with a calculator providing exact $95 \%$ Poisson CIs, available at http://home.clara.net/sisa/ smr.htm.

We next examined age as a risk factor for dementia by estimating its unadjusted odds ratio (OR), as well as unadjusted ORs for gender and ID level. A logistic regression analysis was then undertaken to determine the independent effect of age by entering these risk factors and their interactions simultaneously.

\section{Results}

\section{Participants}

After removing the names of all adults known to have died, moved away, or who were known to have DS, 281 potential participants were identified. Of these, $24(8.5 \%)$ were ineligible for the study because of unrecorded DS status, being too young, having died recently, not having an ID, or were not contactable at the given address. Of the remaining 257 individuals, $222(86.4 \%)$ participated in the survey. Participants did not differ significantly from non-participants in terms of age or sex. The age range of participants was 60-94 years, with a mean of 68.8 years (S.D. $=7.45$ ). Further demographic details of participants are given in Table 1.

Sixty $(27 \%)$ participants screened positive for symptoms of dementia or cognitive decline and participated in the full assessment stage of the study. Women were more likely to screen positive $(37.1 \%$
Table 1. Demographic details of participants

\begin{tabular}{|c|c|c|c|}
\hline Demographic & $n$ & $\%$ & Total $(n)$ \\
\hline Age (in 5-year bands) & & & 222 \\
\hline $60-64$ & 80 & 36.0 & \\
\hline $65-69$ & 59 & 26.6 & \\
\hline $70-74$ & 37 & 16.7 & \\
\hline $75-79$ & 21 & 9.5 & \\
\hline $80-84$ & 14 & 6.3 & \\
\hline$\geqslant 85$ & 11 & 5.0 & \\
\hline Sex & & & 222 \\
\hline Male & 117 & 52.7 & \\
\hline Female & 105 & 47.3 & \\
\hline Ethnicity & & & 222 \\
\hline White & 215 & 96.8 & \\
\hline Asian & 6 & 2.7 & \\
\hline Other & 1 & 0.5 & \\
\hline $\begin{array}{l}\text { Severity of intellectual } \\
\text { disability (ID) }\end{array}$ & & & 222 \\
\hline Mild ID & 123 & 55.4 & \\
\hline Moderate ID & 70 & 31.5 & \\
\hline More severe ID & 29 & 13.1 & \\
\hline Type of residence & & & 222 \\
\hline $\begin{array}{c}\text { Independent or less } \\
\text { than 24-h support }\end{array}$ & 74 & 33.3 & \\
\hline 24-h support & 115 & 51.8 & \\
\hline Nursing homes or hospital & 33 & 14.9 & \\
\hline Health problems & & & 222 \\
\hline No problems & 37 & 16.7 & \\
\hline One or more problems & 183 & 82.4 & \\
\hline Mental health problems & & & 222 \\
\hline No problems & 129 & 58.1 & \\
\hline One or more problems & 93 & 41.9 & \\
\hline $\begin{array}{l}\text { Hearing problems } \\
\text { (assessed with participant) }\end{array}$ & & & 200 \\
\hline No hearing problem & 105 & 52.5 & \\
\hline Minimal loss & 54 & 27.0 & \\
\hline Moderate loss & 29 & 14.5 & \\
\hline Deaf or near deaf & 12 & 6.0 & \\
\hline $\begin{array}{l}\text { Vision problems } \\
\text { (assessed with participant) }\end{array}$ & & & 184 \\
\hline No vision problem & 48 & 26.1 & \\
\hline $\begin{array}{l}\text { Mild to moderate } \\
\text { impairment }\end{array}$ & 124 & 67.4 & \\
\hline Blind or near blind & 12 & 6.5 & \\
\hline Mobility problems & & & 222 \\
\hline Walks without help & 140 & 63.1 & \\
\hline $\begin{array}{l}\text { Requires aid/s or } \\
\text { wheelchair bound }\end{array}$ & 82 & 36.9 & \\
\hline
\end{tabular}

v. $17.9 \%$, Pearson's $\chi^{2}$ statistic $10.38, p=0.001$ ). Those screening negative were significantly younger than the screen positives [67.1 years (S.D. $=6.2) v .73 .6$ years (s.D. $=8.5) ; t=-6.24, p<0.001]$. 
Table 2. Prevalence rates in 5-year bands for criteria-defined dementia cases, and criteria-defined plus potential cases

\begin{tabular}{|c|c|c|c|}
\hline Age band (yr) & $\begin{array}{l}\text { Number of } \\
\text { participants }\end{array}$ & $\begin{array}{l}\text { Criteria-defined } \\
\text { dementia cases } \\
\% \text { (counts) }\end{array}$ & $\begin{array}{l}\text { Criteria-defined } \\
\text { dementia plus } \\
\text { potential cases } \\
\% \text { (counts) }\end{array}$ \\
\hline $60-64$ & 80 & $3.8(3)$ & $7.5(6)$ \\
\hline $65-69$ & 59 & $8.5(5)$ & $15.3(9)$ \\
\hline $70-74$ & 37 & $8.1(3)$ & $24.3(9)$ \\
\hline $75-79$ & 21 & $33.3(7)$ & $47.6(10)$ \\
\hline $80-84$ & 14 & $35.7(5)$ & $42.9(6)$ \\
\hline$\geqslant 85$ & 11 & $54.5(6)$ & $72.7(8)$ \\
\hline $\begin{array}{l}\geqslant 60 \\
(95 \% \mathrm{CI})\end{array}$ & 222 & $\begin{array}{l}13.1(29) \\
(8.9-18.2)\end{array}$ & $\begin{array}{l}21.6(48) \\
(16.4-27.6)\end{array}$ \\
\hline $\begin{array}{l}\geqslant 65 \\
(95 \% \mathrm{CI})\end{array}$ & 142 & $\begin{array}{l}18.3(26) \\
(12.3-25.7)\end{array}$ & $\begin{array}{l}29.6(42) \\
(22.2-37.8)\end{array}$ \\
\hline $\begin{array}{l}\text { Men } \\
\quad(95 \% \text { CI })\end{array}$ & 71 & $\begin{array}{l}14.1(10) \\
(7.0-24.4)\end{array}$ & $\begin{array}{l}21.1(15) \\
(12.3-33.4)\end{array}$ \\
\hline $\begin{array}{l}\text { Women } \\
(95 \% \mathrm{CI})\end{array}$ & 71 & $\begin{array}{l}22.5(16) \\
(13.5-34.0)\end{array}$ & $\begin{array}{l}38.0(27) \\
(26.8-50.3)\end{array}$ \\
\hline
\end{tabular}

CI, Confidence interval.

\section{Dementia cases and potential cases}

The participants were divided into three groups, depending on their dementia status:

(1) Those who definitely did not have dementia: 174 participants $(78.4 \%)$ were in this category.

(2) Criteria-defined dementia cases: 29 participants $(13.1 \%)$ met any dementia criteria.

(3) Potential cases: 19 (8.6\%) participants who did not have sufficient information to decide either way.

We combined criteria-defined and potential cases in some analyses.

\section{Dementia prevalence}

The overall prevalence for criteria-defined dementia cases was $13.1 \%$ (95\% CI 8.9-18.2) in those aged 60 and older and $18.3 \%$ (95\% CI 12.3-25.7) in those aged $\geqslant 65$ years. Five-year prevalence rates for both criteria-defined cases and criteria-defined combined with potential cases are given in Table 2. Criteriadefined dementia cases were older than other participants [mean age 76.4 years (s.D. $=8.8)$ v. 67.7 years (S.D. $=6.5) ; t=6.41, p<0.001]$ whereas sex differences in prevalence were not statistically significant (men $9.4 \%$, women $17.1 \%$, Pearson's $\chi^{2}=2.92, p=0.087$ ).

\section{Dementia prevalence by ID severity}

The prevalence of criteria-defined dementia did not differ according to severity of ID (prevalence rate of those with mild, moderate and severe ID was 14.6, 14.3 and $3.4 \%$ respectively; Pearson's $\chi^{2}=2.72$, $p=0.26$ ). The median ages for these three groups were similar, at 67, 67 and 66 respectively. However, potential cases were more common in those with severe ID compared to the rest $5.2 \%$ in those with mild or moderate ID $v .31 .0 \%$ in those with severe ID; Fisher's exact test $p<0.001)$ (Table 1).

\section{Comparison with general population rates}

The observed prevalence for dementia in adults with ID aged $\geqslant 60$ years was compared to the expected rate from a recent consensus study (Ferri et al. 2005), which resulted in an SMR of 2.4 (95\% CI 1.6-3.5). The prevalence rate for adults with ID aged $\geqslant 65$ years was compared with the expected rate from a large UK urban population study (Saunders et al. 1993). The SMR for this comparison was 3.9 (95\% CI 2.5-5.7).

\section{Age-associated dementia risk}

Age, adjusted for ID level dichotomized as mild and moderate to profound, was significantly associated with dementia (OR 1.15 per year, 95\% CI 1.09-1.22, $p<0.001)$ and did not change when sex was added to the model (OR 1.15 per year, 95\% CI 1.09-1.22, $p<0.001)$. Results were similar when potential cases were included. The interaction terms age by sex and age by ID level were explored and neither revealed a significant association with dementia. In a final model, age, sex, ID level and both interaction terms were 
entered together. Age remained a significant predictor for dementia (OR 1.15 per year, 95\% CI 1.05-1.25, $p=0.003)$.

We combined criteria-defined dementia cases with potential cases to remove the potential bias due to diagnostic uncertainty and compared these in 5-year age bands with expected counts calculated from the consensus rates for Western Europe (Ferri et al. 2005) and the MRC Alpha study (Saunders et al. 1993). SMRs were calculated and are plotted in Fig. 1. The resulting SMRs increased with decreasing age for both comparisons, so that the SMRs in the 60-65 and 65-70 years age groups were approximately three times that of the $\geqslant 85$ years age group (Fig. 1). This difference remained if the prevalence of criteria-diagnosed dementia cases (without possible cases) was compared to actual community rates from the MRC Alpha study (Saunders et al. 1993) (SMR of 7.7 for those aged 65-69 years, compared to an SMR of 2.7 for those aged $\geqslant 85$ years)

\section{Discussion}

\section{Findings}

We have confirmed that older adults with ID (without DS) have a higher prevalence rate of dementia than other older adults. The dementia prevalence did not differ between those with mild, moderate and severe ID. We also confirmed our hypothesis of a downward shift in age-associated risk when compared with the general population. The association of age with dementia was not affected by ID severity or sex.

\section{Strengths and limitations}

To our knowledge, this is the largest epidemiological study of dementia in people with ID. By including participants from age 60, we were able for the first time to investigate the possibility of a downward shift in age-associated risk for dementia in this population. We identified all potential participants with recognized ID within a defined geographical area, included adults with severe disability, and achieved high participation rates. We have also demonstrated that a more aggressive recruitment strategy would not have resulted in significantly more participants. We collected neuropsychological data, informant histories and data from medical records and completed physical examinations with participants to make diagnoses according to international diagnostic classifications. Our study was powered to estimate the overall prevalence of dementia in this population but may not have sufficient power to make within-group comparisons of prevalence rates. A post-hoc sample size calculation with a power of $80 \%$ and a type 1 error of 0.05 suggests that, to compare the observed

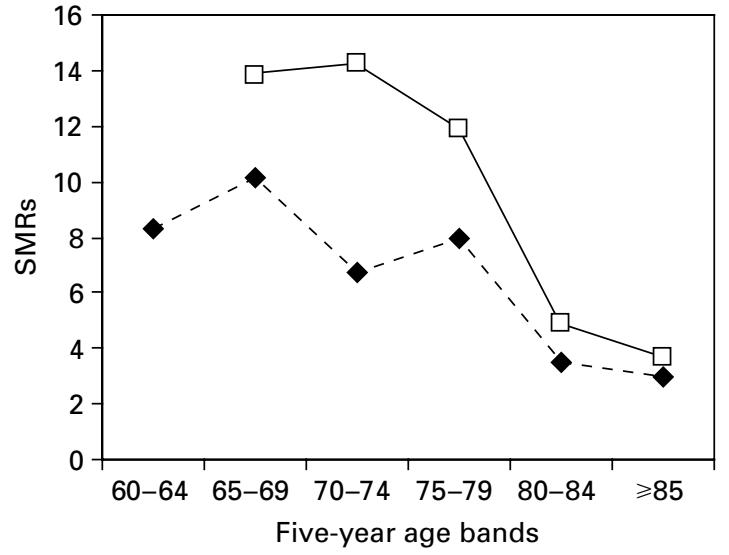

Fig. 1. Standardized morbidity ratios (SMRs) for criteria-diagnosed dementia plus potential cases in 5-year bands. Comparison rates are from the MRC-Alpha study (一 $\square$; Saunders et al. 1993) and the Delphi consensus study (-- - ; Western Europe rates) (Ferri et al. 2005).

dementia prevalence rate in the severe ID group $(n=29)$ with an expected rate in the mild ID group of $14.6 \%$, the sample size required would have needed to be 34 .

It is possible that we have missed some older adults with ID who are unknown to social or health services. However, we believe this number to be small because older adults with ID are likely to need assistance with the functional problems associated with ageing, and this is more likely for older than younger adults to be provided by agencies outside of the family because informal support networks decrease as people grow older. Furthermore, the care system for people with ID in the UK promotes formal assistance and appropriate use of the ID label. Consequently, nearly $90 \%$ of those aged $\geqslant 80$ years receive some form of out-of-home support (Emerson \& Hatton, 2004). It can also be argued that older adults who have managed to live independently of service input throughout their lives are highly unlikely to meet the criteria for mental retardation as defined by the ICD-10 or DSM-IV.

Cross-sectional assessments are less reliable than sequential assessments. We have overcome this limitation by supplementing our assessments with historical information from informants or medical records, but for a proportion of participants we were not able to decide whether they had dementia or not. The extremely limited cognitive and communication abilities of participants with severe ID was associated with diagnostic uncertainty. Furthermore, dementia criteria may have limitations in the ID population and the reliability and predictive validity has not yet been demonstrated. ICD-10 dementia criteria missed dementia cases of moderate severity in this population 
(Strydom et al. 2007). Our study may therefore have underestimated the true prevalence of dementia. A more definitive estimation will only be possible with a cohort design that includes post-mortem examination. Finally, the sample was drawn from London boroughs in the UK and may not be representative of all older adults with ID because of the tendency to place adults with higher needs outside of cities in areas where suitable housing and care settings are more readily available. This could have further reduced the prevalence of dementia as the study population may be healthier and more functionally able than the ID population in other areas of the UK.

\section{Prevalence of dementia in people with ID}

The prevalence of criteria-defined dementia in this survey was $13.1 \%$ in those aged $\geqslant 60$ years and $18.3 \%$ in those aged $\geqslant 65$ years. The prevalence of dementia was not influenced by ID level but diagnostic uncertainty (possible cases) increased with increasing severity of ID, and this may have masked underlying differences.

There have been two previous community estimates of the prevalence of dementia in this population in Europe. Both reported rates comparable to ours. Patel et al. (1993) reported a prevalence of $8.3 \%$ in 96 adults with moderate and more severe ID aged $\geqslant 50$ years in Oldham, UK and Cooper (1997) found a prevalence of $20.2 \%$ in a sample of 129 adults aged $\geqslant 65$ years in Leicester, also in the UK. Both these studies had smaller numbers of participants and were less representative of those with mild ID than the present study. There has only been one North American study to date, which found no difference in SMR for dementia in adults with ID than that of the general population (Zigman et al. 2004). However, their sample was small $(n=126)$ and the sampling method was potentially biased in that it consisted of a sample drawn from known service users combined with a sample of convenience, and only included Alzheimer's dementia. Because of the methodological variation between previous surveys it is difficult to make comparisons with the present study, but additional support for our finding of an increased prevalence of dementia in this population is from a study that demonstrated that adults with low IQ (borderline intelligence) had an elevated incidence of dementia when compared to others with normal intelligence (Schmand et al. 1997).

\section{Severity of ID and mortality}

Adults with ID have high levels of health morbidity and consequently often die at younger ages than their peers; increased mortality is especially pronounced in the groups with severe ID and in those with additional problems such as epilepsy (Patja et al. 2000; Gustavson et al. 2005). As age is the strongest aetiological factor associated with dementia and has an exponential effect, this may influence the proportion of adults affected in the oldest old, or those with severe disability. These differential mortality rates may result in a cohort of healthy survivors, who may be less susceptible to dementia. Indeed, once an adult with ID without DS has reached age 65 , their life expectancy is comparable to that of the general population (Haveman, 2004). The healthy cohort effect may be another reason for the relatively low rates of dementia in the severe ID group.

\section{Age as risk factor for dementia in ID}

This is, to our knowledge, the first study that has investigated the theoretical shift in age-associated risk in adults with ID. Dementia in this population of adults with ID appears to begin at an earlier age than expected. This is in keeping with the cognitive reserve theory, which predicted a younger age of onset in this group. It is further supported by the finding that smaller brain size has been associated with earlier onset of symptoms (Schofield et al. 1995). An accelerated decline (Scarmeas et al. 2006) and higher mortality (Geerlings et al. 1999) have been noted when dementia occurs in adults with high ability or educational attainment, giving support to the idea that, in contrast to the present participants, they can tolerate some degree of pathology before developing the clinical syndrome associated with it, which then progresses faster because the pathology is more advanced. However, this has not been demonstrated in all such studies (Del Ser et al. 1999). Whether adults with ID and dementia will have a faster rate of progression, or higher mortality, needs to be studied further.

An alternative hypothesis is that some of the underlying causes of ID might also confer increased vulnerability to dementia in later life. It is also possible that the lower SMRs for dementia in the oldest group compared to the younger groups might be explained by increased mortality in adults with ID and dementia.

\section{Policy implications and future research}

Our findings indicate that adults with non-DS ID are more likely than the general population to develop cognitive decline and dementia. Like adults with DS, those with symptoms suggestive of dementia need to be offered assessment to enable early identification and intervention. Other areas for policy and service provision include the provision of accommodation 
and community facilities that is suitable for frail and vulnerable older people.

Our study needs to be confirmed with incidence studies of sufficient sample size, which is especially important because prevalence studies may underestimate the underlying incidence due to the elevated mortality rate in this population. Incidence studies can also help to reduce diagnostic uncertainty, which could underestimate the true risk for dementia in prevalence studies. Older adults with ID are a highrisk population for dementia, and further studies may help us to better understand the factors associated with the disorder. This is also an important population in which to test the efficacy of non-drug interventions to reduce the risk of dementia.

\section{Acknowledgements}

This study was funded by the Medical Research Council (UK) with a Training Fellowship Grant to A.S. (G106/1160). Additional support was provided by the Penrose Society in the form of a Jancar Travelling Fellowship to A.S. We thank all the participants and their carers, and local area clinicians and social services staff involved in this study. Our protocol benefited from discussions with Professor Tony Holland, and training to A.S. by Mr Paul Patti, Dr Arthur Dalton and others at the New York State Institute for Basic Research in Developmental Disabilities. The research was supported by the R\&D departments of Oxleas NHS Trust, Harrow Primary Care Trust (PCT), Enfield PCT, Islington PCT and Camden PCT, who all receive a proportion of funding from the NHS Executive; the views expressed in this publication are those of the authors and not necessarily those of the funders or the NHS Executive.

\section{Declaration of Interest}

None.

\section{References}

Albert M, Cohen C (1992). The test for severe impairment: an instrument for the assessment of patients with severe cognitive dysfunction. Journal of the American Geriatrics Society 40, 449-453.

APA (2000). Diagnostic and Statistical Manual of Mental Disorders DSM-IV-TR (Text Revision). American Psychiatric Association: Washington, DC.

Ball SL, Holland AJ, Huppert FA, Treppner P, Watson P, Hon J (2004). The modified CAMDEX informant interview is a valid and reliable tool for use in the diagnosis of dementia in adults with Down's syndrome. Journal of Intellectual Disability Research 48, 611-620.
Burt DB, Aylward EH (2000). Test battery for the diagnosis of dementia in individuals with intellectual disability. Journal of Intellectual Disability Research 44, 175-180.

Cooper SA (1997). High prevalence of dementia among people with learning disabilities not attributable to Down's syndrome. Psychological Medicine 27, 609-616.

Del Ser T, Hachinski V, Merskey H, Munoz DG (1999). An autopsy-verified study of the effect of education on degenerative dementia. Brain 122, 2309-2319.

Dunn LM, Dunn LM, Whetton C, Burley J (1997). British Picture Vocabulary Scale, 2nd edn. NFER-Nelson: Windsor.

Emerson E, Hatton C (2004). Estimating the Current Need/ Demand for Supports for People with Learning Disabilities in England. Institute for Health Research, Lancaster University: Lancaster.

Evenhuis HM (1996). Further evaluation of the Dementia Questionnaire for Persons with Mental Retardation (DMR). Journal of Intellectual Disability Research 40, 369-373.

Ferri CP, Prince M, Brayne C, Brodaty $H$, Fratiglioni L, Ganguli M, Hall K, Hasegawa K, Hendrie H, Huang YQ, Jorm A, Mathers C, Menezes PR, Rimmer E, Scazufca M (2005). Global prevalence of dementia: a Delphi consensus study. Lancet 366, 2112-2117.

Geerlings MI, Deeg DJH, Penninx BWJH, Schmand B, Jonker C, Bouter LM, van Tilburg W (1999). Cognitive reserve and mortality in dementia: the role of cognition, functional ability and depression. Psychological Medicine 29, 1219-1226.

Gustavson KH, Umb-Carlsson O, Sonnander K (2005). A follow-up study of mortality, health conditions and associated disabilities of people with intellectual disabilities in a Swedish county. Journal of Intellectual Disability Research 49, 905-914.

Hassiotis A, Strydom A, Allen K, Walker Z (2003). A memory clinic for older people with intellectual disabilities. Aging and Mental Health 7, 418-423.

Haveman MJ (2004). Disease epidemiology and ageing people with intellectual disabilities. Journal of Policy and Practice in Intellectual Disabilities 1, 16-23.

Lawton MP, Brody EM (1969). Assessment of older people: self-maintaining and instrumental activities of daily living. The Gerontologist 9, 179-186.

McKeith IG, Galasko D, Kosaka K, Perry EK, Dickson DW, Hansen LA, Salmon DP, Lowe J, Mirra SS, Byrne EJ, Lennox G, Quinn NP, Edwardson JA, Ince PG, Bergeron C, Burns A, Miller BL, Lovestone S, Collerton D, Jansen ENH, Ballard C, Devos RAI, Wilcock GK, Jellinger KA, Perry RH (1996). Consensus guidelines for the clinical and pathologic diagnosis of dementia with Lewy bodies (DLB): report of the consortium on DLB international workshop. Neurology 47, 1113-1124.

McKhann GM, Albert MS, Grossman M, Miller B, Dickson D, Trojanowski JQ (2001). Clinical and pathological diagnosis of frontotemporal dementia: report of the work group on frontotemporal dementia and Pick's disease. Archives of Neurology 58, 1803-1809.

Moss S (2002). The Mini-PASADD Interview Pack. Pavilion: Brighton. 
Nihira K, Leland L, Lambert N (1992). Adaptive Behaviour Scale: Residential and Community, 2nd edn. Pro-ed: Austin, TX.

Page RM, Cole GE, Timmreck TC (1995). Basic Epidemiological Methods and Biostatistics: A Practical Guidebook. Jones and Bartlett: Boston.

Patel P, Goldberg D, Moss S (1993). Psychiatric morbidity in older people with moderate and severe learning disability. 2. The Prevalence Study. British Journal of Psychiatry 163 481-491.

Patja K, Iivanainen M, Vesala H, Oksanen H, Ruoppila I (2000). Life expectancy of people with intellectual disability: a 35-year follow-up study. Journal of Intellectual Disability Research 44, 591-599.

Randall Smith (2005). Human Rights, Anti-Discrimination and Disability in Britain. School for Policy Studies, University of Bristol: Bristol, UK.

Saunders PA, Copeland JRM, Dewey ME, Gilmore C, Larkin BA, Phaterpekar H, Scott A (1993). The prevalence of dementia, depression and neurosis in later life: the Liverpool MRC-Alpha study. International Journal of Epidemiology 22, 838-847.

Saxton J, Swihart AA (1989). Neuropsychological assessment of the severely impaired elderly patient. Clinics in Geriatric Medicine 5, 531-543.

Scarmeas N, Albert SM, Manly JJ, Stern Y (2006). Education and rates of cognitive decline in incident Alzheimer's disease. Journal of Neurology, Neurosurgery and Psychiatry 77, 308-316.

Schmand B, Smit JH, Geerlings MI, Lindeboom J (1997). The effects of intelligence and education on the development of dementia. A test of the brain reserve hypothesis. Psychological Medicine 27, 1337-1344.

Schofield PW, Mosesson RE, Stern Y, Mayeux R (1995). The age at onset of Alzheimer's disease and an intracranial area measurement. A relationship. Archives of Neurology 52, 95-98.

Shallice T (1982). Specific impairments of planning. Philosophical Transactions of the Royal Society of London, Series B. Biological Sciences 298, 199-209.

Staff RT, Murray AD, Deary IJ, Whalley LJ (2004). What provides cerebral reserve? Brain 127, 1191-1199.

Stern Y (2002). What is cognitive reserve? Theory and research application of the reserve concept.
Journal of the International Neuropsychological Society 8, 448-460.

Stern Y (2003). The concept of cognitive reserve: a catalyst for research. Journal of Clinical and Experimental Neuropsychology 25, 589-593.

Strydom A, Livingston G, King M, Hassiotis A (2007). Prevalence of dementia in intellectual disability using different diagnostic criteria. British Journal of Psychiatry 191, 150-157.

Thompson CW (1951). Decline in limit of performance among adult morons. American Journal of Psychology 64, 203-215.

Torr J (2005). Dementia and intellectual disability. In Dementia (ed. A. Burns, J. T. O'Brien and D. Ames), pp. 745-749. Hodder Arnold: London.

Tredgold AF (1952). Amentia with other forms of mental disease. In Mental Deficiency (ed. A. F. Tredgold), pp. 394-395. Bailliere, Tindall and Cox: London.

Troyer AK (2000). Normative data for clustering and switching on verbal fluency tasks. Journal of Clinical and Experimental Neuropsychology 22, 370-378.

Valenzuela MJ, Sachdev P (2006). Brain reserve and dementia: a systematic review. Psychological Medicine 36, 441-454.

Verghese J, Lipton RB, Katz MJ, Hall CB, Derby CA, Kuslansky G, Ambrose AF, Sliwinski M, Buschke H (2003). Leisure activities and the risk of dementia in the elderly. New England Journal of Medicine 348, 2508-2516.

Whalley LJ, Deary IJ, Appleton CL, Starr JM (2004). Cognitive reserve and the neurobiology of cognitive aging. Ageing Research Reviews 3, 369-382.

Whalley LJ, Starr JM, Athawes R, Hunter D, Pattie A, Deary IJ (2000). Childhood mental ability and dementia. Neurology 55, 1455-1459.

WHO (1993). The ICD-10 Classification of Mental and Behavioural Disorders: Diagnostic Criteria for Research. World Health Organization: Geneva.

Zigman WB, Schupf N, Devenny DA, Miezejeski C, Ryan R, Urv TK, Schubert R, Silverman W (2004). Incidence and prevalence of dementia in elderly adults with mental retardation without Down syndrome. American Journal on Mental Retardation 109, 126-141. 